\title{
Assessment of the Antibacterial Effects of Bismuth Nanoparticles against Enterococcus faecalis
}

\author{
Azita Azad (D), ${ }^{1}$ Sahar Rostamifar $\left(\mathbb{D},{ }^{2}\right.$ Farzan Modaresi $\left(\mathbb{D},{ }^{3}\right.$ Ali Bazrafkan $(\mathbb{D})^{2}$ \\ and Zahra Rezaie iD ${ }^{4}$ \\ ${ }^{1}$ Oral and Dental Disease Research Center, Department of Oral \& Maxillofacial Medicine, School of Dentistry, Shiraz University of \\ Medical Sciences, Shiraz, Iran \\ ${ }^{2}$ Student Research Committee, School of Dentistry, Shiraz University of Medical Sciences, Shiraz, Iran \\ ${ }^{3}$ Departments of Microbiology, Advanced Medical Sciences and Technology, And Central Laboratory Research, Jahrom University of \\ Medical Sciences, Jahrom, Iran \\ ${ }^{4}$ Student Research Committee, Jahrom University of Medical Sciences, Jahrom, Iran
}

Correspondence should be addressed to Farzan Modaresi; modarresifarzan@gmail.com

Received 22 May 2020; Revised 1 October 2020; Accepted 6 October 2020; Published 23 October 2020

Academic Editor: Ameh James

Copyright (c) 2020 Azita Azad et al. This is an open access article distributed under the Creative Commons Attribution License, which permits unrestricted use, distribution, and reproduction in any medium, provided the original work is properly cited.

Introduction. Enterococcus faecalis (E. faecalis) is the most important species in dentistry and plays a significant role in the etiology of persistent apical lesions after root canal treatment. Up to date, the intracanal application of $2 \%$ chlorhexidine for 7 days is the best way to eliminate E. faecalis. However, due to the ability of this bacterium to persist and survive in harsh environments, many studies have been directed towards finding an alternative strategy for prevention or eradication of it. This study was conducted to investigate the effect of bismuth nanoparticles on E. faecalis, as an etiologic factor in recurrent root canal infections. Methods. Forty patients, referred to Endodontic Ward of Shiraz University of Medical Science for endodontic pretreatment, provided root canal samples. First, all samples were transferred in Enterococcosel broth and incubated. Then, samples which showed growth were plated on blood agar plates and incubated for further PCR procedure. Nanoparticle powder was dissolved in high-purity water, and the final concentration of bismuth nanoparticles (BiNPs) was measured by the spectrophotometer. Minimum inhibitory concentration (MIC) of BiNPs against E. faecalis was determined by microbroth dilution method according to methods for antimicrobial susceptibility tests. Also, bactericidal assays were conducted in Mueller-Hinton broth medium and reported as the concentration of BiNPs that reduced the viable bacterial count by $99.9 \%$. Results. Of all samples, $77.5 \%$ revealed the presence of E. faecalis by PCR. Also, E. faecalis growth inhibition was observed at concentrations ranging from $0.625 \mu \mathrm{g} / \mathrm{ml}$ to $20 \mu \mathrm{g} / \mathrm{ml}$ (geometric mean: $2.337 \mu \mathrm{g} / \mathrm{ml}$ ), and the MBC values were between $1.25 \mu \mathrm{g} / \mathrm{ml}$ and $40 \mu \mathrm{g} / \mathrm{ml}$ (geometric mean: $4.781 \mu \mathrm{g} / \mathrm{ml}$ ), which in comparison with chlorhexidine, these values were about one-eighth of chlorhexidine. Conclusion. The experimental data suggest that bismuth nanoparticles could be an interesting alternative to combat E. faecalis, which, in view of the advantages mentioned for bismuth nanoparticle like inhibiting Streptococcus mutans biofilm formation and higher antibacterial activity compared to chlorhexidine, can be suggested to be used in different fields of dentistry.

\section{Introduction}

Enterococcus faecalis as a member of Enterococcus genus is a Gram-positive, facultative anaerobe that most commonly found as the commensal in the gastrointestinal tract (including the oral cavity) and the urogenital system. Of all Enterococci species, E. faecalis is the most important species in dentistry due to their role in dental diseases, including endodontic infections, periodontitis, and dental caries $[1,2]$. In this regard, studies have shown a significant association of E. faecalis with the occurrence of endodontic treatment failures [3]. Unlike primary intraradicular infections, which are polymicrobial and predominated by Gram-negative anaerobic rods, the organisms involved in secondary infections are 
limited to one or a few bacterial species [4]. E. faecalis is a persistent microorganism that, in spite of making a small part of the flora in untreated canals, plays an important role in the etiology of persistent apical lesions after root canal treatment. It is usually found in a high percentage of endodontic failures and it can remain alive in the root canal as a single microorganism or as a main constituent of the flora [4]. The presence of E. faecalis is associated with different forms of endodontic infection, such as primary and persistent endodontic infections. In primary infections, it is more often found in asymptomatic chronic periradicular lesions than in acute periradicular periodontitis or abscesses. It is isolated in 4 to $40 \%$ of primary endodontic infections, while its frequency in teeth with failed treatment is nine times more [5]. Studies using culture methods for isolation of Enterococci in secondary endodontic infections reported a prevalence between 24 and $77 \%$, whilst using a PCR method results in an isolation rate ranging from 67 to $77 \%$ [6], so the molecular methods can be a benefit in this regard due to their high sensitivity and accuracy, among which multiplex polymerase chain reaction (PCR) is one of the latest [7]. Indeed, E. faecalis can be one of the substantial factors in root canal treatment failures, and its presence at the time of obturation might significantly reduce the treatment success rates [8]. Its pathogenicity primarily relies upon its survival and persistence in the root canals, although it has additional virulence factors, such as the ability to attach and forms biofilm on host surfaces [9]. Many studies have investigated different endodontic medicaments and irrigant to eradicate and/or prevent $E$. faecalis from gaining access to the root canal system during treatment. For instance, $3 \%$ to full-strength sodium hypochlorite can destroy E. faecalis, including its existence as a biofilm [10]. EDTA and $10 \%$ citric acid solution have a little antibacterial effect against E. faecalis activity; however, they have the capability to remove the inorganic part of the smear layer, allowing other irrigants to reach to the dentinal tubules [11]. Also, MTAD, a new root canal irrigant consisting of a mixture of tetracycline, an acid, and detergent, has demonstrated a promising ability to eradicate E. faecalis [12]. Likewise, $2 \%$ chlorhexidine gel or liquid is effective in eliminating $E$. faecalis from superficial layers and dentinal tubules, which may be assigned to substantive antimicrobial effect [13]. Other irrigants which showed to be effective at eliminating E. faecalis include stannous fluoride and ozonated water [14]. On the other hand, calcium hydroxide, a commonly used intracanal medicament, showed to be almost ineffective against these bacteria [15]. Furthermore, the antibacterial activities of several sealers have also been examined against E. faecalis, with Roth 811, a zinc oxide eugenol-based sealer, having the strongest inhibitory effects [16]. Until further investigations, the intracanal application of $2 \%$ chlorhexidine for 7 days is reported to be the best way to eliminate E. faecalis $[17,18]$. However, due to the ability of this bacterium to persist and survive in harsh environments as well as the emerging resistance among Enterococcus spices, many studies have been directed towards finding an alternative strategy for prevention or eradication of E. faecalis from the root canal system [1]. Amongst these strategies, nano- particles, typically $0.2-100 \mathrm{~nm}$ in size, showed good results as novel antimicrobial agents. Their privilege might be due to their high surface-to-volume ratio, which increases the interactions between these particles and microorganisms, improving their inhibitory effects [19]. Also, the differences in size and surface area between these particles and conventional antimicrobial agents can reduce the chance of developing resistance [19]. Up to now, the metals most frequently used for biomedical applications include gold, titanium, silver, copper, zinc, magnesium, and bismuth [20]. Bismuth (Bi) is a diamagnetic, crystalline, and brittle metal of the VA group, typically found as bismuth sulfide, bismuth oxide, and bismuth carbonate [21]. Studies have shown that bismuth derivatives and its nanoparticulate forms inhibit Helicobacter pylori growth by altering their Krebs cycling, amino acid, and nucleotide metabolisms, and they can be used as an antidiarrheal agent to treat nausea, vomiting, and stomach pain [22]. Additionally, it was reported that BiNPs exhibited antibacterial and antifungal activities at concentrations lower than $1 \mathrm{mM}$ and $2 \mathrm{mM}$, respectively $[23,24]$. Also, they can interfere with the biofilm formation of $S$. mutans, the main etiological agent of dental decays [23]. However, bismuth nanoscale particles' potential for application in dentistry has not been extensively studied, and the present study was conducted to investigate the effect of BiNPs on the standard strain and clinical isolates of E. faecalis, as an etiologic factor in recurrent root canal infections.

\section{Methods}

2.1. Sample Taking. Forty patients, ages from 18 to 45 years old, including 22 males and 18 females, referred to Endodontic Ward of Shiraz University of Medical Science for endodontic pretreatment, provided root canal samples, which were then analyzed for the presence of E. faecalis. All samples were obtained from patients who had rooted canal therapy completed more than 1 year ago. Patients who were pregnant, diabetic, smoker, and those requiring pretreatment due to missing canals, broken instruments, perforations, ledges, or calcified root canals were excluded. None of the selected teeth have termini of the root canal filling more than $5 \mathrm{~mm}$ short in radiographic findings and periodontal pockets deeper than $4 \mathrm{~mm}$. After supragingival scaling and isolation with a rubber dam, samples were taken by one of the authors as previously described by Gomes et al. [13]. The tooth and the adjacent field were decontaminated with a $2.5 \%$ sodium hypochlorite for $30 \mathrm{~s}$ each and then inactivated with $5 \%$ sodium thiosulfate. As the previous restorations were removed and the access cavities prepared, the pulp chambers were disinfected with $5.25 \%$ sodium hypochlorite, and the obturation materials were removed with ProTaper nickeltitanium rotary instruments SX-F2 (WNT, India) under irrigation with sterile saline. The microbial samples were collected by inserting two sterile paper points into the working length of the canal and keeping them in place for $60 \mathrm{~s}$. The debris on the paper points were transferred into sterile $2 \mathrm{ml}$ Eppendorf tubes containing viability medium Gotenberg agar III transport medium and evaluated immediately within 2 hrs. After shaking the samples in a mixer for $60 \mathrm{~s}$ (Vortex, 
TABLE 1: Oligonucleotide used in this study for identification of Enterococcus faecalis by PCR [25].

\begin{tabular}{lccc}
\hline Target DNA & Sequence of primer $\left(5^{\prime}-3^{\prime}\right)$ & Condition & Amplicon size $(\mathrm{pb})$ \\
\hline \multirow{2}{*}{$16 \mathrm{~S}$ rRNA } & GTTTATGCCGCATGGCATAAGA & $95^{\circ} \mathrm{C}-2 \mathrm{~min} ; 36 \mathrm{cycles}\left(95^{\circ} \mathrm{C}-30 \mathrm{~s} ; 60^{\circ} \mathrm{C}\right.$ & 310 \\
& G CCGTCAGGGGACGTTCAG & $\left.-60 \mathrm{~s} ; 72^{\circ} \mathrm{C} 60 \mathrm{~s}\right)$ and $72^{\circ} \mathrm{C}-2 \mathrm{~min}$ & \\
\hline
\end{tabular}

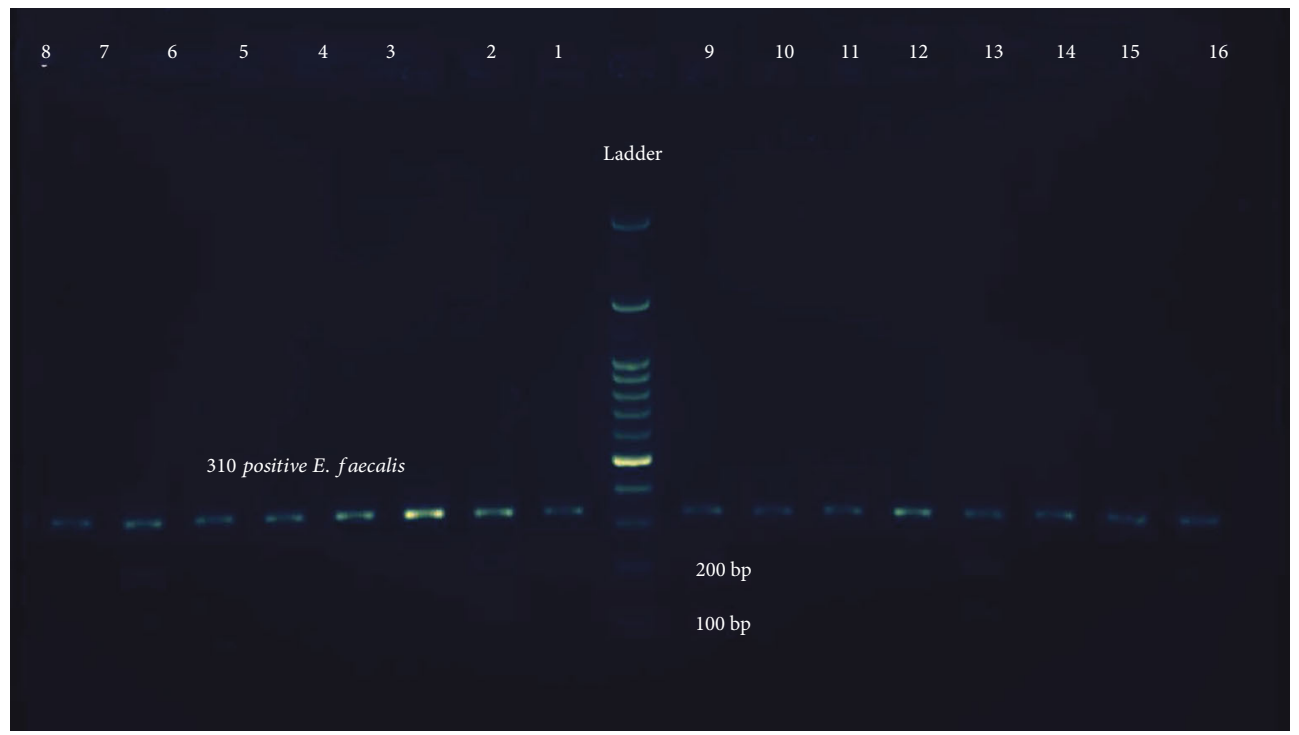

FIGURE 1: Electrophoresis of E. faecalis 16S rRNA gene on 1\% agarose gel. The target gene was of 310 bp. Lane 1: control positive. Lanes 2-16: PCR product of $16 \mathrm{~S}$ rRNA gene (310 bp); ladder: $100 \mathrm{bp}$ DNA size marker.

Scientific Industries Inc., Springfield, MA), $1 \mathrm{ml}$ of each sample were used for culture, and the other $1 \mathrm{ml}$ were frozen at $-20^{\circ} \mathrm{C}$ for by PCR procedures [13]. Additionally, a standard strain of E. faecalis (ATCC 51299) obtained from the American Type Culture Collection was studied.

The study was approved by the Ethics Committee of Shiraz University of Medical Science (96-01-03-14924). Patients were informed of the study procedures and goals, and written consent was obtained.

2.2. Culture and Identification Procedures. First, all samples were transferred into Enterococcosel broth (HiMedia, India) and incubated for $72 \mathrm{~h}$ at $35^{\circ} \mathrm{C}$. Then, samples which showed growth were plated on blood agar plates (Plast Labor, Rio de Janeiro, RJ, Brazil) and incubated at $35^{\circ} \mathrm{C}$ for further usages [8].

2.3. PCR Procedures. One-milliliter aliquots from positive cultures in Enterococcosel broth (HiMedia, India) were transferred to microtubes, and DNA was extracted by boiling as described by Siqueira and Rocas (2004). Gene that encode for $16 \mathrm{~S}$ rRNA of E. faecalis was targeted. The entire PCR products were loaded into $1 \%$ agarose (Cinnagen, Tehran, Iran) gel and electrophoresed (Akhtarian, Tehran, Iran) for $1-1.5 \mathrm{~h}$ in the $1 \times$ TAE buffer along with a molecular weight marker. After staining with ethidium bromide (Merck), the DNA bands were visualized under UV illumination (UVP Gel Documentation, Upland, CA, USA), and the prevalence of $E$. faecalis was reported as the percentage of cases investi- gated. Primer sequence and PCR condition used for identification of E. faecalis is shown in Table 1 [25].

2.4. Preparation and Characterization of BiNP Solution. Eight milligrams of nanoparticle powder (Nano Scientific Co, USA) were dissolved in $200 \mathrm{ml}$ of high-purity water and sonicated (Biometra, Germany) for 20 minutes at 900 watts. The sonicated solution was sterilized by passing through a $0.2 \mu \mathrm{m}$ filter (Control Biogene, Spain), and the final concentration of BiNPs was measured by the spectrophotometer (Eppendrof, Germany). The shape, size, and distribution of synthesized BiNPs have been characterized by the high-resolution transmission electron microscopy (TEM) with a JEM 1011 microscope (JEM-1011 “JEOL LTD,” Japan).

2.5. Bacterial Suspension. Overnight grown cultures of $E$. faecalis strains in TSA broth (HiMedia, India) at $37^{\circ} \mathrm{C}$ were centrifuged at $6000 \mathrm{rpm}$ for $4 \mathrm{~min}$ (Eppendrof, Germany), and the supernatants were discarded. The collected cells were washed twice with sterile distilled water. Subsequently, the cells were suspended in $5 \mathrm{ml}$ of TSA broth and incubated for $4 \mathrm{~h}$ at $37^{\circ} \mathrm{C}$, and their concentrations were adjusted to match the turbidity of $0.5 \mathrm{McF}$ arland using a spectrophotometer.

2.6. Antimicrobial Susceptibility Testing. Minimum inhibitory concentration (MIC) of BiNPs against E. faecalis was determined by microbroth dilution method according to methods for antimicrobial susceptibility tests for bacteria that grow aerobically, 11th edition. Starter cultures of E. 
TABLE 2: Characteristics of the patients and presence of E. faecalis.

\begin{tabular}{|c|c|c|c|c|c|c|c|}
\hline Patient no. & Age (year) & Gender $(\mathrm{M} / \mathrm{F})$ & Presence of E. faecalis & Patient no. & Age (year) & Gender $(\mathrm{M} / \mathrm{F})$ & Presence of E. faecalis \\
\hline 1 & 19 & $\mathrm{M}$ & + & 21 & 43 & $\mathrm{~F}$ & + \\
\hline 2 & 29 & $\mathrm{~F}$ & + & 22 & 31 & M & + \\
\hline 3 & 20 & M & + & 23 & 30 & M & + \\
\hline 4 & 41 & M & - & 24 & 28 & $\mathrm{~F}$ & - \\
\hline 5 & 22 & $\mathrm{~F}$ & + & 25 & 20 & $\mathrm{~F}$ & + \\
\hline 6 & 18 & $\mathrm{~F}$ & + & 26 & 45 & M & + \\
\hline 7 & 45 & $\mathrm{~F}$ & - & 27 & 45 & M & + \\
\hline 8 & 40 & M & + & 28 & 33 & $\mathrm{~F}$ & - \\
\hline 9 & 33 & M & + & 29 & 20 & M & + \\
\hline 10 & 30 & $\mathrm{M}$ & + & 30 & 29 & $\mathrm{M}$ & + \\
\hline 11 & 32 & $\mathrm{M}$ & + & 31 & 30 & $\mathrm{~F}$ & + \\
\hline 12 & 39 & $\mathrm{M}$ & + & 32 & 36 & $\mathrm{~F}$ & + \\
\hline 13 & 19 & $\mathrm{~F}$ & - & 33 & 37 & $\mathrm{~F}$ & + \\
\hline 14 & 27 & $\mathrm{M}$ & - & 34 & 20 & $\mathrm{M}$ & + \\
\hline 15 & 21 & $\mathrm{~F}$ & + & 35 & 19 & $\mathrm{M}$ & - \\
\hline 16 & 35 & $\mathrm{M}$ & + & 36 & 24 & $\mathrm{~F}$ & - \\
\hline 17 & 19 & $\mathrm{~F}$ & + & 37 & 34 & $\mathrm{M}$ & + \\
\hline 18 & 37 & $\mathrm{~F}$ & + & 38 & 31 & $\mathrm{M}$ & + \\
\hline 19 & 26 & $\mathrm{M}$ & - & 39 & 24 & $\mathrm{~F}$ & + \\
\hline 20 & 36 & $\mathrm{M}$ & + & 40 & 40 & $\mathrm{~F}$ & + \\
\hline
\end{tabular}

faecalis were grown at $35^{\circ} \mathrm{C}$ for $4 \mathrm{~h}$ at $200 \mathrm{rpm}$ and used to make $0.5-\mathrm{McF}$ arland standard suspensions, which were further diluted at a ratio of $1: 100\left(5 \times 10^{5} \mathrm{CFU} / \mathrm{ml}\right)$ in Mueller-Hinton broth medium (HiMedia, India). In brief, $10 \mu \mathrm{l}$ of bacterial inoculum was added to Mueller-Hinton broth medium containing $100 \mu \mathrm{l}$ of serial dilutions of BiNPs in the wells of microtiter plates (Cinnagen, Tehran, Iran). The final concentration of BiNPs ranged from 40 to $1 \mu \mathrm{g} / \mathrm{ml}$. One hundred microliters of culture medium with $10 \mu \mathrm{l}$ of the bacterial inoculum without BiNPs was used as a negative control group. Also, chlorhexidine 2\% (Oral-B, USA) ranging from 100 to $1 \mu \mathrm{l} / \mathrm{ml}$ was used as the positive control. The plates were incubated at $37^{\circ} \mathrm{C}$ for $24 \mathrm{~h}$, and the minimum inhibitory concentrations were visually determined and represented as the lowest concentration of the BiNPs that inhibited the bacterial growth as compared with control groups. Each experiment was performed in triplicate. Also, bactericidal assays were conducted in a Mueller-Hinton broth medium. Minimal bactericidal concentrations were reported as the concentration of BiNPs that reduced the viable bacterial count by $99.9 \%$ at $24 \mathrm{~h}$ of incubation. Viable bacterial counts were determined by standard plating on Mueller-Hinton agar media [26].

\section{Results}

3.1. Identification of E. faecalis by PCR Procedure. Forty adult patients consisted of 22 men and 18 women with a mean age of 30.175 (range from 18 to 45 years) were provided samples in the study. Thirty-one out of 40 samples (77.5\%) revealed the presence of $E$. faecalis by PCR identification tech-

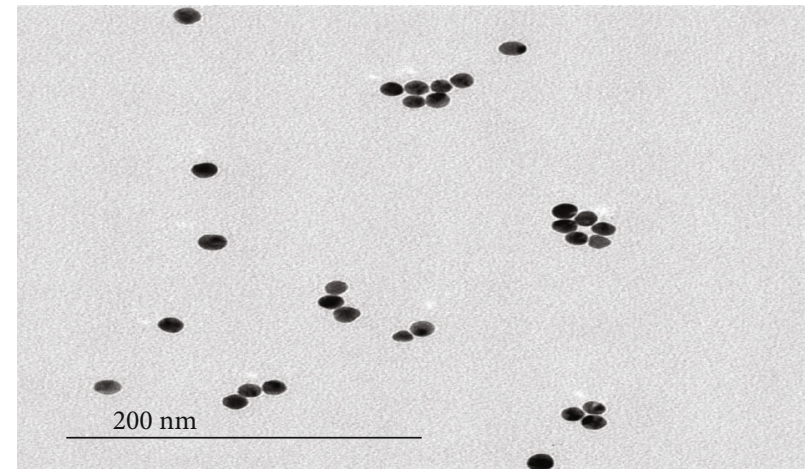

FIGURE 2: High-resolution transmission electron microscopic image of an isolated bismuth nanoparticles performed by JEOL Jem 1011 Electron Microscope.

nique loaded into $1 \%$ agarose electrophoresis gel (Figure 1). However, eleven root canal samples $(22.5 \%)$ showed no growth of bacteria. Details regarding subjects were presented in Table 2.

3.2. BiNPs Characterization. Water dispersion of BiNPs has been produced with the aim of their antimicrobial activity estimation against E. faecalis. By transmission electron microscopy, it has been found that nanoparticles have an average particles' size of $40 \mathrm{~nm}$ with spherical form (Figure 2).

3.3. Antimicrobial Susceptibility Testing. To explore the possible antibacterial activity of bismuth nanoparticles, their 
TABLe 3: MIC and MBC values of BiNPs against E. faecalis.

\begin{tabular}{|c|c|c|c|c|c|c|c|}
\hline Patient no. & $\begin{array}{l}\text { Presence of } \\
\text { E. faecalis }\end{array}$ & $\begin{array}{l}\text { The MIC of } \\
\operatorname{BiNP}(\mu \mathrm{g} / \mathrm{ml})\end{array}$ & $\mathrm{MBC}$ of $\mathrm{BiNP}$ & Patient no. & $\begin{array}{l}\text { Presence of } \\
\text { E. faecalis }\end{array}$ & $\begin{array}{l}\text { The MIC of } \\
\operatorname{BiNP}(\mu \mathrm{g} / \mathrm{ml})\end{array}$ & $\mathrm{MBC}$ of $\mathrm{BiNP}$ \\
\hline 1 & + & 2.5 & 5 & 21 & + & 1.25 & 2.5 \\
\hline 2 & + & 5 & 10 & 22 & + & 5 & 10 \\
\hline 3 & + & 1.25 & 2.5 & 23 & + & 5 & 5 \\
\hline 4 & - & - & - & 24 & - & - & - \\
\hline 5 & + & 2.5 & 5 & 25 & + & 2.5 & 5 \\
\hline 6 & + & 5 & 5 & 26 & + & 1.25 & 5 \\
\hline 7 & - & - & - & 27 & + & 1.25 & 5 \\
\hline 8 & + & 20 & 40 & 28 & - & - & - \\
\hline 9 & + & 2.5 & 5 & 29 & + & 5 & 10 \\
\hline 10 & + & 1.25 & 2.5 & 30 & + & 2.5 & 5 \\
\hline 11 & + & 0.625 & 2.5 & 31 & + & 0.625 & 1.25 \\
\hline 12 & + & 1.25 & 5 & 32 & + & 0.625 & 1.25 \\
\hline 13 & - & - & - & 33 & + & 5 & 10 \\
\hline 14 & - & - & - & 34 & + & 2.5 & 5 \\
\hline 15 & + & 5 & 10 & 35 & - & - & - \\
\hline 16 & + & 10 & 20 & 36 & - & - & - \\
\hline 17 & + & 2.5 & 5 & 37 & + & 1.25 & 1.25 \\
\hline 18 & + & 0.625 & 1.25 & 38 & + & 0.625 & 1.25 \\
\hline 19 & - & - & - & 39 & + & 5 & 10 \\
\hline 20 & + & 1.25 & 2.5 & 40 & + & 10 & 20 \\
\hline
\end{tabular}

effect on $E$. faecalis growth was determined. The results showed $E$. faecalis growth inhibition at concentrations ranging from $0.625 \mu \mathrm{g} / \mathrm{ml}$ to $20 \mu \mathrm{g} / \mathrm{ml}$ (geometric mean: $2.337 \mu \mathrm{g} / \mathrm{ml}$ ). Also, the MBC values were between $1.25 \mu \mathrm{g} / \mathrm{ml}$ and $40 \mu \mathrm{g} / \mathrm{ml}$ (geometric mean: $4.781 \mu \mathrm{g} / \mathrm{ml}$ ). Regarding the standard strain of $E$. faecalis, the MIC and MBC values of BiNPs were $5 \mu \mathrm{g} / \mathrm{ml}$ and $10 \mu \mathrm{g} / \mathrm{ml}$, respectively. This was while the MIC and MBC values of chlorhexidine were recorded as $40 \mu \mathrm{l} / \mathrm{ml}$ and $80 \mu \mathrm{l} / \mathrm{ml}$. Table 3 shows the MIC and $\mathrm{MBC}$ value of all tested isolates towards BiNPs.

\section{Discussion}

Amongst the Enterococci species isolated from root canals, $E$. faecalis is the most common species; however, it constitutes a small proportion of the microbial species isolated from root canals. In this study, the prevalence of E. faecalis among the selected patients was recorded as $77.5 \%$. Also, previous researches studying the existence of $E$. faecalis in root-filled teeth with periapical lesions have reported a wide range of prevalence from 24 to $77 \%$ which can be due to the differences in the methods of identification $[5,27,28]$. Additionally, other studies have isolated E. faecalis in teeth with prior unsuccessful treatment with a range of $30 \%$ to $90 \%$ [ 5 , 29]. Most of these studies have been conducted using culturing methods. These methods have provided great insight into the microbiology of endodontic diseases. However, molecular studies have several superiorities when compared with culture. Molecular methods, particularly, polymerase chain reaction (PCR), are more accurate, more predictable, more sensitive, and faster techniques, which may justify the higher prevalence of E. faecalis in this study [2]. Antimicrobial drug resistance among Enterococci species has encouraged development of alternative therapeutic strategies. Amongst these strategies, nanomaterials have turned up as noteworthy and innovative antimicrobial agents [30]. Transmission electron microscopy (TEM), high-resolution TEM (HRTEM), and low-resolution TEM (LRTEM) had facilitated the characterization of NPs and revolutionized their use [31]. Due to the advantages of nanoparticles, several studies have been conducted on the antibacterial effects of nanoparticles, most of which on silver nanoparticles. For example, the study of Sadeghi et al. regarding the comparison of the antimicrobial effect of silver nanoparticles and chlorhexidine on Streptococcus sanguis and Actinomyces viscosis showed that silver nanoparticle had an antimicrobial effect better than chlorhexidine [32]. Furthermore, in the study of Niakan et al., they compared the effect of silver nanoparticles with Deconex disinfectants on Staphylococcus aureus and Pseudomonas aeruginosa and found that silver nanoparticles antimicrobial effect is superior [33]. In this work, we focused on the effectiveness of bismuth nanoparticles in inhibiting the growth of E. faecalis, by broth microdilution method, a standard method which is more accurate, reliable, and easier to interpret compared to other methods such as well diffusion method [34], although the inhibitory effect of elemental bismuth is detected at comparatively high concentrations because of its limited water solubility. However, lower concentrations can be attained with chelating agents such as dimercaptopropanol. Bismuth-dimercaptopropanol has high 
solubility with reduced antimicrobial activity [35]. Nevertheless, our results showed more effective antibacterial activity of BiNPs against $E$. faecalis in comparison with chlorhexidine, in a way that the MIC and MBC of bismuth nanoparticles were about one-eighth of chlorhexidine.

Chlorhexidine, as a gold standard for the removal of microbial plaque, has a strong antiseptic effect, and studies comparing the effect of chlorhexidine with other antibacterial products show that chlorhexidine has a stronger antibacterial effect on dental plaque microorganisms than other substances. For example, Haffajee et al. showed that chlorhexidine mouthwash has a stronger antimicrobial effect than herbal mouthwashes [36]. However, it can cause complications such as discoloration of the teeth and tongue, taste disturbance, and it also increases the risk of oropharyngeal cancers due to the high alcohol content (12\%), which necessitates the use of other therapeutic strategies [37]. Overall, the experimental data suggest that bismuth nanoparticles could be an interesting alternative to combat E. faecalis, which, in view of the advantages mentioned for bismuth nanoparticle like inhibiting Streptococcus mutans biofilm formation and higher antibacterial activity compared to chlorhexidine, can be suggested to be used in different fields of dentistry. However, there is still insufficient research into long-term effects as well as its complications on human beings, and its use requires more extensive studies. In addition, the compatibility of nanoparticles with the nature and the method of their recovery requires more researches.

\section{Conclusion}

The experimental data suggest that bismuth nanoparticles could be an interesting alternative to combat E. faecalis, which, in view of the advantages mentioned for bismuth nanoparticle like inhibiting Streptococcus mutans biofilm formation and higher antibacterial activity compared to chlorhexidine, can be suggested to be used in different fields of dentistry.

\section{Data Availability}

The experimental and clinical data used to support the findings of this study are included within the article.

\section{Disclosure}

This study is part of a dentistry thesis (no. 14924).

\section{Conflicts of Interest}

The authors declare no conflicts of interest.

\section{Authors' Contributions}

The authors alone are responsible for the content and writing of the paper.

\section{Acknowledgments}

The authors thank the vice chancellery of Shiraz University of Medical Sciences for supporting the research (grant no. $960103-14924$ ). This manuscript is relevant to the thesis of Dr. Sahar Rostamifar. The authors thank Dr. M. Vosoughi from the Dental Research Development Center for the statistical analysis.

\section{References}

[1] E. Radeva and D. Karayasheva, "Importance of Enterococci (Enterococcus faecalis) for dental medicine - microbiological characterization, prevalence and resistance," International Journal of Science and Research, vol. 6, no. 7, pp. 1970-1973, 2017.

[2] C. H. Stuart, S. A. Schwartz, T. J. Beeson, and C. B. Owatz, "Enterococcus faecalis: its role in root canal treatment failure and current concepts in retreatment," Journal of Endodontics, vol. 32, no. 2, pp. 93-98, 2006.

[3] M. Nayak, S. Kotigadde, H. Shetty, R. Vineet, and B. Antony, "Impact of Peptostreptococcus on type 2 diabetes mellitus related secondary root canal infections," International Journal of Pharmaceutical Sciences and Research, vol. 4, no. 10, p. 4001, 2013.

[4] G. Sundqvist, D. Figdor, S. Persson, and U. Sjögren, "Microbiologic analysis of teeth with failed endodontic treatment and the outcome of conservative re-treatment," Oral Surgery, Oral Medicine, Oral Pathology, Oral Radiology, and Endodontology., vol. 85, no. 1, pp. 86-93, 1998.

[5] I. N. Rôças, J. F. Siqueira Jr., and K. R. Santos, "Association of Enterococcus faecalis with different forms of periradicular diseases," Journal of Endodontics, vol. 30, no. 5, pp. 315-320, 2004.

[6] Z. Mohammadi, "Effects of root canal irrigants on the planktonic form of Enterococcus faecalis: a review," Nigerian Journal of Medicine, vol. 24, no. 3, pp. 261-267, 2015.

[7] A. Azad, F. Modaresi, M. Zahed, M. Zarei, A. Ranjbaran, and Z. K. Jahrom, "Multiplex polymerase chain reaction for detection of bacteremia during dental extraction," Journal of Investigative and Clinical Dentistry, vol. 10, article e12425, 2019.

[8] G. O. Zoletti, E. M. Pereira, R. P. Schuenck, L. M. Teixeira, J. F. Siqueira, and K. R. N. dos Santos, "Characterization of virulence factors and clonal diversity of Enterococcus faecalis isolates from treated dental root canals," Research in Microbiology, vol. 162, no. 2, pp. 151-158, 2011.

[9] R. Love, "Enterococcus faecalis-a mechanism for its role in endodontic failure," International Endodontic Journal, vol. 34, no. 5, pp. 399-405, 2001.

[10] J. Siqueira Jr., A. Machado, R. Silveira, H. Lopes, and M. De Uzeda, "Evaluation of the effectiveness of sodium hypochlorite used with three irrigation methods in the elimination of Enterococcus faecalis from the root canal, in vitro," International Endodontic Journal, vol. 30, no. 4, pp. 279-282, 1997.

[11] M. Torabinejad, A. Khademi, J. Babagoli et al., "A new solution for the removal of the smear layer," Journal of Endodontics, vol. 29, no. 3, pp. 170-175, 2003.

[12] S. Shabahang and M. Torabinejad, "Effect of MTAD on Enterococcus faecalis-contaminated root canals of extracted human teeth," Journal of Endodontics, vol. 29, no. 9, pp. 576579,2003 
[13] B. P. Gomes, E. T. Pinheiro, C. R. Gade-Neto et al., "Microbiological examination of infected dental root canals," Oral Microbiology and Immunology, vol. 19, no. 2, pp. 71-76, 2004.

[14] M. Nagayoshi, T. Fukuizumi, C. Kitamura, J. Yano, M. Terashita, and T. Nishihara, "Efficacy of ozone on survival and permeability of oral microorganisms," Oral microbiology and immunology., vol. 19, no. 4, pp. 240-246, 2004.

[15] Y.-h. Lin, A. K. Mickel, and S. Chogle, "Effectiveness of selected materials against Enterococcus faecalis: part 3. The antibacterial effect of calcium hydroxide and chlorhexidine on Enterococcus faecalis," Journal of Endodontics, vol. 29, no. 9, pp. 565-566, 2003.

[16] A. MICKEL, T. NGUYEN, and S. CHOGLE, "Antimicrobial activity of endodontic sealers on Enterococcus faecalis," Journal of Endodontics, vol. 29, no. 4, pp. 257-258, 2003.

[17] B. P. F. A. Gomes, S. F. C. Souza, C. C. R. Ferraz et al., "Effectiveness of $2 \%$ chlorhexidine gel and calcium hydroxide againstEnterococcus faecalisin bovine root dentinein vitro," International Endodontic Journal, vol. 36, no. 4, pp. 267-275, 2003.

[18] B. Basrani, J. M. Santos, L. Tjäderhane et al., "Substantive antimicrobial activity in chlorhexidine-treated human root dentin," Oral Surgery, Oral Medicine, Oral Pathology, Oral Radiology, and Endodontology., vol. 94, no. 2, pp. 240-245, 2002.

[19] G. Rudramurthy, M. Swamy, U. Sinniah, and A. Ghasemzadeh, "Nanoparticles: alternatives against drug resistant pathogenic microbes," Molecules, vol. 21, no. 7, p. 836, 2016

[20] S. M. Dizaj, A. Mennati, S. Jafari, K. Khezri, and K. Adibkia, "Antimicrobial activity of carbon-based nanoparticles," Advanced Pharmaceutical Bulletin, vol. 5, no. 1, p. 19, 2015.

[21] C.-R. Claudio and S. Chellam, Bismuth nanoparticles: antimicrobials of broad-spectrum, low cost and safety, Nanomedicine; A. Seifalian, A. Mel, and D. M. Kalaskar, Eds., pp. 430-437, 2014.

[22] D. Figueroa-Quintanilla, E. Salazar-Lindo, R. B. Sack et al., “A controlled trial of bismuth subsalicylate in infants with acute watery diarrheal disease," New England Journal of Medicine, vol. 328, no. 23, pp. 1653-1658, 1993.

[23] C. Cabral-Romero, Hernandez-Delgadillo, Velasco-Arias et al., "Zerovalent bismuth nanoparticles inhibit Streptococcus mutans growth and formation of biofilm," International Journal of Nanomedicine, vol. 7, p. 2109, 2012.

[24] C. Cabral-Romero, R. Hernandez-Delgadillo, M.-S. VelascoArias, D. Diaz, and N.-A. Zumeta-Dubé, "Bismuth oxide aqueous colloidal nanoparticles inhibit Candida albicans growth and biofilm formation," International Journal of Nanomedicine, vol. 8, p. 1645, 2013.

[25] J. F. Siqueira Jr. and I. N. Rôças, "Polymerase chain reactionbased analysis of microorganisms associated with failed endodontic treatment," Oral Surgery, Oral Medicine, Oral Pathology, Oral Radiology, and Endodontology, vol. 97, no. 1, pp. 8594, 2004

[26] K. R. Halkai, J. A. Mudda, V. Shivanna, V. Rathod, and R. Halkai, "Antibacterial efficacy of biosynthesized silver nanoparticles against Enterococcus faecalis biofilm: an in vitro study," Contemporary Clinical Dentistry, vol. 9, no. 2, pp. 237-241, 2018.
[27] A. F. Fouad, J. Zerella, J. Barry, and L. S. Spångberg, "Molecular detection of Enterococcus species in root canals of therapyresistant endodontic infections," Oral Surgery, Oral Medicine, Oral Pathology, Oral Radiology, and Endodontology, vol. 99, no. 1, pp. 112-118, 2005.

[28] A. C. Anderson, A. Al-Ahmad, F. Elamin et al., "Comparison of the bacterial composition and structure in symptomatic and asymptomatic endodontic infections associated with root-filled teeth using pyrosequencing," PLoS One, vol. 8, no. 12, article e84960, 2013.

[29] E. Pinheiro, B. Gomes, C. Ferraz, E. Sousa, F. Teixeira, and F. Souza-Filho, "Microorganisms from canals of root-filled teeth with periapical lesions," International Endodontic Journal, vol. 36, no. 1, pp. 1-11, 2003.

[30] V. Ravishankar Rai and B. A. Jamuna, Nanoparticles and their potential application as antimicrobials, A. A Méndez-Vilas, Ed., Mysore: Formatex, 2011.

[31] M. J. Hajipour, K. M. Fromm, A. A. Ashkarran et al., "Antibacterial properties of nanoparticles," Trends in Biotechnology, vol. 30, no. 10, pp. 499-511, 2012

[32] R. Sadeghi, P. Owlia, R. Mb, F. Taleghani, and F. Sharif, “An in-vitro comparison between antimicrobial activity of nanosilver and chlorhexidine against Streptococus sanguis and Actinomyces viscosus," The Journal of Islamic Dental Association of IRAN, vol. 23, no. 4, p. 22531, 2011.

[33] M. Niakan, F. Abassi, R. Hamedi, E. Aliasghar, F. Najafi, and M. Fatemi, "Antibacterial effect of nanosilver colloidal particles and its comparison with dental disinfectant solution against two strains of bacteria," Daneshvar Medicine, vol. 19, no. 96, pp. 65-72, 2012.

[34] F. Cockerill and Clinical, Institute LS, Methods for dilution antimicrobial susceptibility tests for bacteria that grow aerobically: approved standard, Clinical and Laboratory Standards Institute, 2012.

[35] A. R. Badireddy, R. Hernandez-Delgadillo, R. I. SánchezNájera, S. Chellam, and C. Cabral-Romero, "Synthesis and characterization of lipophilic bismuth dimercaptopropanol nanoparticles and their effects on oral microorganisms growth and biofilm formation," Journal of Nanoparticle Research, vol. 16, no. 6, p. 2456, 2014.

[36] A. D. Haffajee, T. Yaskell, and S. S. Socransky, "Antimicrobial effectiveness of an herbal mouthrinse compared with an essential oil and a chlorhexidine mouthrinse," The Journal of the American Dental Association, vol. 139, no. 5, pp. 606-611, 2008.

[37] M. G. Newman, H. Takei, P. R. Klokkevold, and F. A. Carranza, Newman and Carranza's Clinical Periodontology EBook, Elsevier Health Sciences, 2018. 